Check for updates

Cite this: Chem. Sci., 2019, 10, 11023

๑ All publication charges for this article have been paid for by the Royal Society of Chemistry

Received 11th September 2019 Accepted 8th October 2019

DOI: $10.1039 / \mathrm{c} 9 \mathrm{sc} 04584 \mathrm{~h}$

rsc.li/chemical-science

\section{Reactivity control of a photocatalytic system by changing the light intensity $\dagger$}

\author{
Christoph Kerzig (D) * and Oliver S. Wenger (D)*
}

We report a novel light-intensity dependent reactivity approach allowing us to selectively switch between triplet energy transfer and electron transfer reactions, or to regulate the redox potential available for challenging reductions. Simply by adjusting the light power density with an inexpensive lens while keeping all other parameters constant, we achieved control over one- and two-photon mechanisms, and successfully exploited our approach for lab-scale photoreactions using three substrate classes with excellent selectivities and good product yields. Specifically, our proof-of-concept study demonstrates that the irradiation intensity can be used to control (i) the available photoredox reactivity for reductive dehalogenations to selectively target either bromo- or chloro-substituted arenes, (ii) the photochemical cis-trans isomerization of olefins versus their photoreduction, and (iii) the competition between hydrogen atom abstraction and radical dimerization processes.

\section{Introduction}

The interplay of several photocatalyst properties such as molar absorption coefficients, excited-state energies, redox potentials, excited-state lifetimes and photostabilities determines the yield and selectivity of a given photo(redox) reaction. Therefore, it comes as no surprise that, under standardized conditions, every photoreaction has one ideal catalyst that needs to be identified. In direct consequence, a whole library of photoactive molecules with tailor-made properties has been prepared over the last few decades, by both organic ${ }^{1-4}$ and inorganic ${ }^{5-12}$ chemists.

To overcome the need for several, frequently expensive catalysts with optimized properties, the concept of wavelength dependence and wavelength selectivity ${ }^{13}$ has been exploited to control the redox potential of single photocatalysts by regulating the irradiation light color. ${ }^{14,15}$ In a somewhat related approach, a photocatalytic allylation was combined with a lightcolor selective isomerization to control product formation. ${ }^{16}$ While these recent chromoselective methods ${ }^{15,16}$ are very elegant and clearly have an impact on photoredox catalysis, they both rely on irradiation equipment consisting of at least two high-power LEDs as light sources.

An attractive alternative, but yet underexplored strategy to gain control over photochemical reactivity is provided by regulating the light intensity while keeping all other parameters constant. The approach of intensity dependent one- (low intensity) and two-photon (high intensity) chemistry is rather

Department of Chemistry, University of Basel, St. Johanns-Ring 19, 4056 Basel, Switzerland.E-mail: christoph.kerzig@unibas.ch; oliver.wenger@unibas.ch

$\dagger$ Electronic supplementary information (ESI) available: Comprehensive experimental details, further mechanistic investigations, control experiments and application-related details. See DOI: $10.1039 / \mathrm{c} 9 \mathrm{sc0} 0584 \mathrm{~h}$ well-established under laser flash photolysis conditions, ${ }^{\mathbf{1 4}, 17-22}$ which however necessitates expensive pulsed lasers that are inaccessible for most synthetic laboratories. Catalytic cycles comprising the consecutive absorption of two photons with an excited state as intermediate (i.e., without converting the excited state into a long-lived radical anion) ${ }^{23,24}$ were realized under continuous wave (cw) excitation conditions only very recently. ${ }^{25}$ The feasibility of this new kind of two-photon chemistry on the preparative scale with an inexpensive blue diode laser, ${ }^{26}$ whose acquisition costs are practically identical to those of comparable ready-to-use high-power LEDs, inspired the reactivity control approach presented herein. As we will show, the excitation of our recently developed water-soluble catalyst Irsppy ${ }^{27}$ (see Scheme 1 for its structure) with a single blue photon can initiate several dehalogenation and isomerization reactions, but when a second photon is absorbed within the lifetime of its excited triplet state ( ${ }^{3}$ Irsppy) using higher light intensities per irradiation area, highly aggressive hydrated electrons $\left(\mathbf{e}_{\mathrm{aq}}{ }^{-{ }^{-}}\right)$ that react with the same substrates via a completely different pathway are produced, thereby allowing a fundamentally new reactivity control strategy and its application to selective photo(redox) applications.

\section{Results and discussion}

With a triplet excited state energy of $2.65 \mathrm{eV}$ and an oxidation potential of $1.01 \mathrm{~V} v$ s. $\mathrm{NHE}^{25}{ }^{3}$ Irsppy accessible by one blue photon can either act as sensitizer for challenging triplet-triplet energy transfer reactions ${ }^{28}$ or as photoredox catalyst for many one-electron substrate reductions $\left(E_{1 / 2}\left(\right.\right.$ Irsppy $^{+} /{ }^{3}$ Irsppy $)=$ $-1.64 \mathrm{~V} v$ s. NHE, see also left part of Scheme 1). ${ }^{25,27}$ As we reported recently, the remarkable photostability of Irsppy 


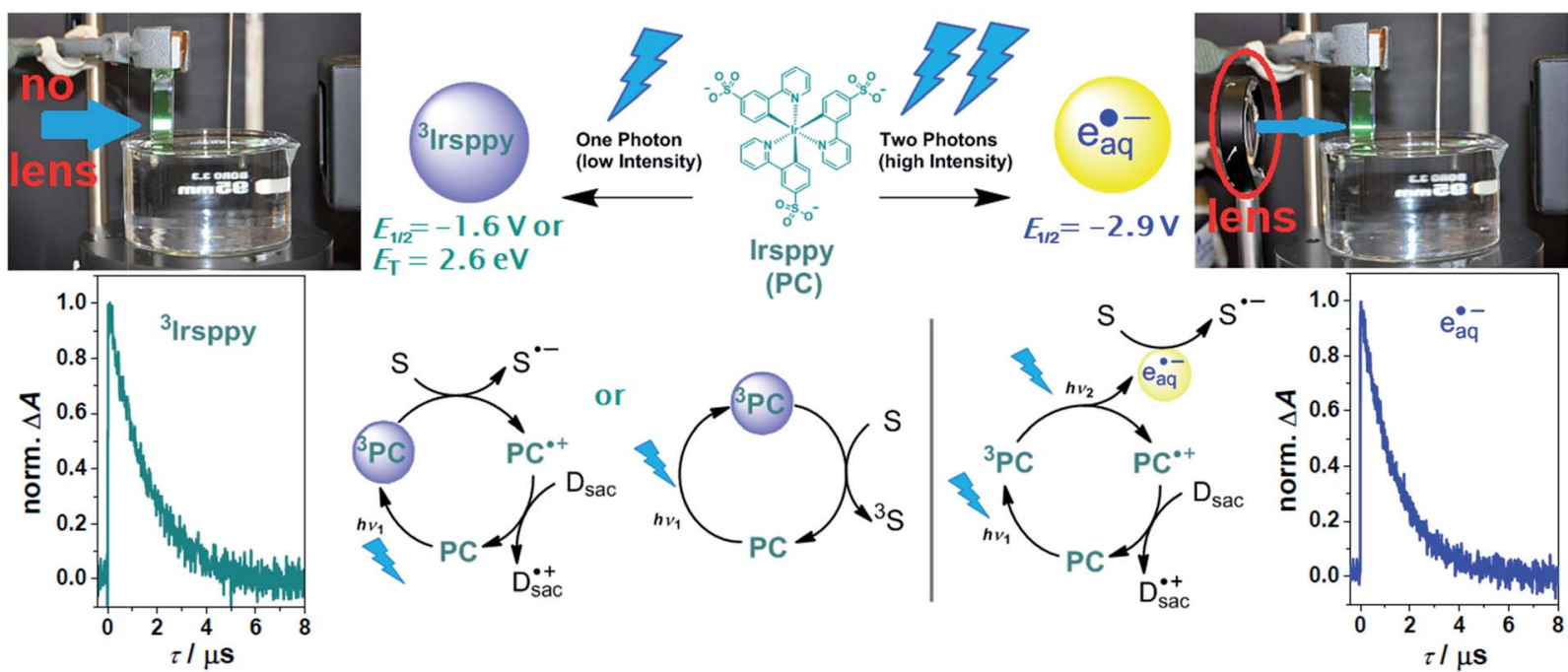

Scheme 1 Reactivity control of our photocatalytic system with a continuous wave (cw) laser ( $447 \mathrm{~nm}, 1 \mathrm{~W}$ ) using the natural laser beam for onephoton excitation (left) or the collimated beam for consecutive two-photon excitation (right). Upper row, structure of the photocatalyst (PC) Irsppy, reactive intermediates produced upon blue one- (left) or two-photon (right) excitation, their reactivities in terms of redox potentials available for reductions $\left(E_{1 / 2}\right.$ vs. NHE) or triplet energy $\left(E_{T}\right)$, as well as photographs illustrating the experimental conditions. Lower row, one- and two-photon mechanisms for substrate (S) activation, and kinetic data showing the unquenched lifetimes of both reactive species ${ }^{3}$ Irsppy and $\mathrm{e}_{\mathrm{aq}}{ }^{\cdot-}$, respectively). For further explanations, see text and ESI. $\dagger$

combined with its favorable excited-state properties, permits an efficient two-photon ionization producing the superreductant $\mathbf{e}_{\mathrm{aq}}{ }^{-{ }^{-}}$with its standard potential of $-2.9 \mathrm{~V} v s$. $\mathrm{NHE},{ }^{29}$ even under cw excitation conditions (right part of Scheme 1). Interestingly, the redox energy available for reductions is almost doubled when going from ${ }^{3}$ Irsppy to $\mathbf{e}_{\mathbf{a q}}{ }^{-}$, whereas the unquenched lifetimes of both species are practically identical in our system (see kinetic data presented in Scheme 1 and Section 1.3 of the ESI for details $\dagger$ ). During our recent investigations on the twophoton ionization of Irsppy $^{25}$ using the chloroacetate assay ${ }^{22,30,31}$ to probe $\mathbf{e}_{\mathrm{aq}}{ }^{-{ }^{-}}$formation, we did not observe any $\mathbf{e}_{\mathrm{aq}}{ }^{\cdot-}$ production with the natural beam of the $447 \mathrm{~nm} \mathrm{cw}$ laser operating at $1 \mathrm{~W}$ optical output (in Scheme 1 , the beam of that laser is visualized by the catalyst emission), but the biphotonic ionization operates efficiently when the diode laser beam is collimated to a spot smaller than $1 \mathrm{~mm}^{2}$ using a lens. In this study, we put to good use a lens as inexpensive key element to switch between one-photon ( ${ }^{3}$ Irsppy) and two-photon $\left(\mathbf{e}_{\mathbf{a q}}{ }^{\cdot-}\right)$ induced lab-scale reactions under otherwise very similar conditions. All photoreactions were carried out in $4 \mathrm{~mL}$ cuvettes with septum caps (pathlength, $10 \mathrm{~mm}$ ) employing triethanolamine (TEOA) as electron donor for catalyst regeneration and hydrogen atom donor allowing the formation of well-defined reaction products. ${ }^{25,32} \mathrm{~A}$ detailed description of our experimental setup is given in Section 3.1 of the ESI. $\dagger$

\subsection{Redox-potential control for reductive dehalogenations}

Thermodynamically, the reductive activation of $\mathrm{C}-\mathrm{Cl}$ bonds is much more challenging than that of $\mathrm{C}-\mathrm{Br}$ bonds, ${ }^{33-35}$ and we speculated that ${ }^{3}$ Irsppy can merely debrominate, whereas $\mathbf{e}_{\mathbf{a q}}{ }^{\cdot-}$ will certainly be able to dechlorinate ${ }^{29}$ as well. As first substrate to test our reactivity control approach, we selected 4-bromo-2- chloro-5-fluorobenzoic acid (which is present as carboxylate under our experimental conditions, see Chapter 3 of the ESI for details $\dagger$ and Fig. 1a for the structure). Efficient activation of the $\mathrm{C}-\mathrm{F}$ bond of that substrate is unlikely to occur, ${ }^{29}$ but the fluoro substituent allows us to exploit ${ }^{19} \mathrm{~F}$ NMR spectroscopy ${ }^{36}$ for selective and sensitive detection of the reaction outcome.

First irradiation experiments ( $3 \mathrm{~h}$ of $447 \mathrm{~nm}$ illumination) using our catalytic system (Irsppy and TEOA in alkaline water) without the lens, i.e., under one-photon conditions, gave the debromination product 2-chloro-5-fluorobenzoic acid in very

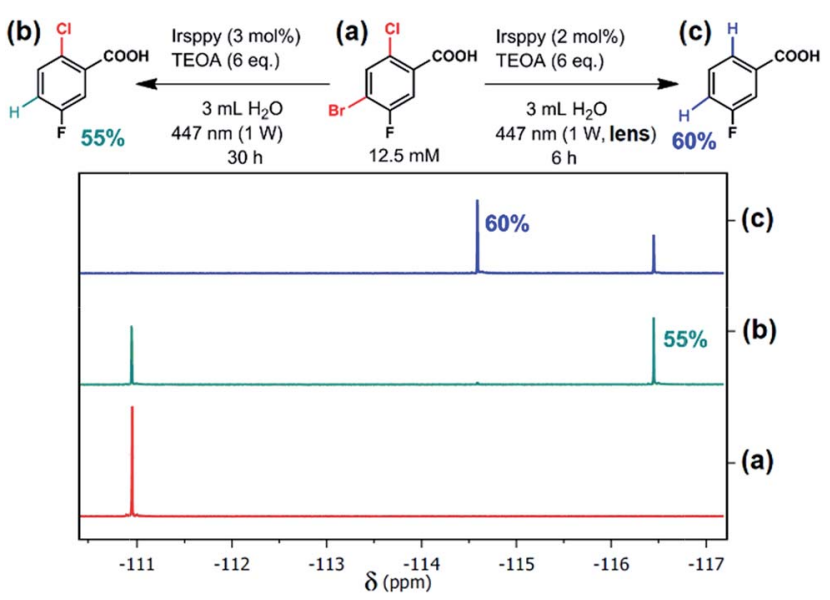

Fig. 1 Selective debromination and subsequent dechlorination carried out with 4-bromo-2-chloro-5-fluorobenzoic acid (a) using the new blue-light driven photocatalytic system in Ar-saturated solutions ((b), one-photon conditions; (c), two-photon conditions) with the reaction parameters given at the equations. Quantitative ${ }^{19} \mathrm{~F}$ NMR measurements are displayed before (a) and after ( $b$ and $c$ ) irradiation. For further details, see text and Section 3.3 of the ESI. $\dagger$ 
low yields (4\%) as observed by quantitative ${ }^{19} \mathrm{~F}$ NMR spectroscopy (for details, see Section 3.3 of the ESI $\dagger$ ). Given that the first mechanistic step, the oxidative quenching of ${ }^{3}$ Irsppy by 4bromo-2-chloro-5-fluorobenzoate, is very slow $\left(\sim 3 \times 10^{5} \mathrm{M}^{-1}\right.$ $\mathrm{s}^{-1}$, Section 2.2 of the ESI $\dagger$ ), a significant increase in catalyst loading and reaction time was necessary to observe acceptable yields of the debromination product (55\%, Fig. 1b). Importantly, only traces of 3 -fluorobenzoic acid $(<1 \%)$ could be detected resulting in a debromination selectivity as high as 62 (Fig. $1 \mathrm{~b}$ and Section 3.3 of the ESI $\dagger$ ).

Simply by putting the lens between cw light source and cuvette (top right photograph in Scheme 1), and irradiating our catalytic system in the presence of the substrate 4-bromo-2chloro-5-fluorobenzoic acid under similar conditions as in Fig. 1b, we observed complete consumption of the starting material and 3-fluorobenzoic acid as main product after six hours (Fig. 1c). The employed two-photon conditions that permit efficient $\mathbf{e}_{\mathbf{a q}}{ }^{\cdot-}$ production evidently initiate not only debromination but also dechlorination. Compared to the onephoton reaction (Fig. 1a), the reduction of the reaction time to $20 \%$ with an even higher yield of the desired two-fold dehalogenated product (Fig. 1c) seems surprising at first glance. However, the diffusion controlled one-electron reduction kinetics of both bromo- and chloro-substituted benzoate derivatives $^{29}$ allowing fast reductive lab-scale dehalogenations provide an explanation for these experimental findings.

The results of this section clearly demonstrate that increasing the thermodynamic reactivity of a catalytic system while maintaining a long lifetime, i.e., a high kinetic reactivity, of the initiating species (longer than 1 microsecond, see Scheme 1) is very beneficial for photoredox applications: first, we introduced the light intensity as selectivity parameter to reductive photoredox activations; second, our approach relying on $\mathbf{e}_{\mathbf{a q}}{ }^{--}$as superreductant ensures relatively short reaction times for challenging and consecutive photoreactions, which otherwise frequently require more than one day of intense photoirradiation. ${ }^{15,35,37}$

\subsection{From triplet-triplet energy transfer (TTET) to electron transfer (ET) chemistry}

Having observed intensity dependent redox-potential regulation for photoreductions, we now turn to the question whether a completely different substrate activation mechanism can operate under one- and two-photon conditions. A one-electron reduction is the only conceivable pathway for $\mathbf{e}_{\mathbf{a q}}{ }^{\cdot-}$ initiated reactions, whereas ${ }^{3}$ Irsppy with its high triplet energy $(2.65 \mathrm{eV}$, see above) could additionally activate substrates through a triplet-triplet energy transfer (TTET) event, which is quite promising given the ongoing rapid development of tripletsensitized photocatalytic reactions. ${ }^{28,38,39}$

Cinnamates, the salts and esters of cinnamic acids, have a (photo)isomerizable double bond with the trans isomer being more stable. Recent photochemical investigations on both the triplet-sensitized trans-cis isomerization ${ }^{\mathbf{2 8 , 4 0 - 4 2}}$ and the hydrated electron induced hydrogenation of double bonds ${ }^{\mathbf{4 3 , 4 4}}$ prompted us to apply our reactivity control approach to this substance class.
We started our studies with unsubstituted trans-cinnamic acid, which was present in its carboxylate form under our experimental conditions (see ESI Section 3.4 for details $\dagger$ ). This substrate has a triplet energy of about $2.4 \mathrm{eV},{ }^{45}$ i.e., more than $0.2 \mathrm{eV}$ lower than that of ${ }^{3}$ Irsppy, thermodynamically allowing a TTET and subsequent double bond isomerization. Using Irsppy as photocatalyst, photoinduced electron transfer can be excluded for thermodynamic reasons since the cinnamate radical anion formation requires a significantly higher $(\sim 0.8$ V) ${ }^{46}$ excited-state oxidation potential than ${ }^{3}$ Irsppy can provide. We indeed observed fast quenching of ${ }^{3}$ Irsppy by the transcinnamate ion. A Stern-Volmer analysis gave a rate constant of $1.20 \times 10^{9} \mathrm{M}^{-1} \mathrm{~s}^{-1}$ (see ESI, Fig. S2 $\dagger$ ), which is in line with diffusion-controlled quenching taking coulombic interactions into account, ${ }^{4,48}$ and we detected the corresponding cis isomer in preparative photolysis experiments employing ${ }^{1} \mathrm{H}$ NMR product analysis (one-photon conditions, 79\% yield, details are given in Section 3.4 of the ESI $\dagger$ ). Collimating the cw laser output with a lens to achieve two-photon conditions for $\mathbf{e}_{\mathbf{a q}}{ }^{\cdot-}$ generation, a novel product was observed in the ${ }^{1} \mathrm{H}$ NMR spectrum, whose signals are in agreement with those of $\beta$-phenylpropionate. ${ }^{46}$ However, a reliable quantification could not be carried out due to spectral overlap of the desired product peaks with trans/cis-cinnamate (aromatic region of the spectrum) and TEOA-derived (aliphatic region) signals.

To circumvent these analytical issues, we turned to trans-3fluorocinnamate as substrate (Fig. 2). The addition of the fluoro substituent to our substrate should only slightly modify the pertinent energetics (as the unchanged TTET kinetics displayed in the lower left part of Fig. 2 indicate), but allows straightforward detection and quantification of both its cis isomer and the corresponding hydrogenated product via ${ }^{19} \mathrm{~F}$ NMR spectroscopy. ${ }^{49}$ Our irradiation studies with trans-3-fluorocinnamate employing this procedure gave $75 \%$ of the cis isomer with the unmodified laser beam (and 25\% remaining trans isomer), whereas a yield of $62 \%$ for the hydrogenation product was observed under two-photon conditions with otherwise unmodified experimental parameters (upper reaction equations in Fig. 2, NMR spectra are shown in Fig. S5 of the ESI $\dagger$ ).

The observed cis-trans-ratio of $3: 1$ does not change upon further irradiation which implies the existence of a photostationary state. Hence, in addition to the quenching rate constant determination for the TTET reaction between ${ }^{3}$ Irsppy and trans3-fluorocinnamate, we performed experiments to investigate whether the cis isomer can be sensitized by ${ }^{3}$ Irsppy as well. Using the very same overall 3-fluorocinnamate concentration, either present as pure trans isomer or as 3:1 cis-to-trans mixture, the comparative ${ }^{3}$ Irsppy lifetime reduction was measured (lower right part of Fig. 2). With the well-defined isomeric mixture as quencher, a longer ${ }^{3}$ Irsppy lifetime, i.e., a slower quenching rate, was clearly detected. A kinetic analysis allowed us to estimate the TTET rate constant between ${ }^{3}$ Irsppy and cis-3-fluorocinnamate, which is about 2.5 times slower than that with the trans isomer (see Section 2.1 of the ESI for details $\dagger$ ). We regard our indirect procedure for quickly estimating the TTET rate with less-stable cis isomers as quenchers as a useful addition to the toolbox of mechanistic 


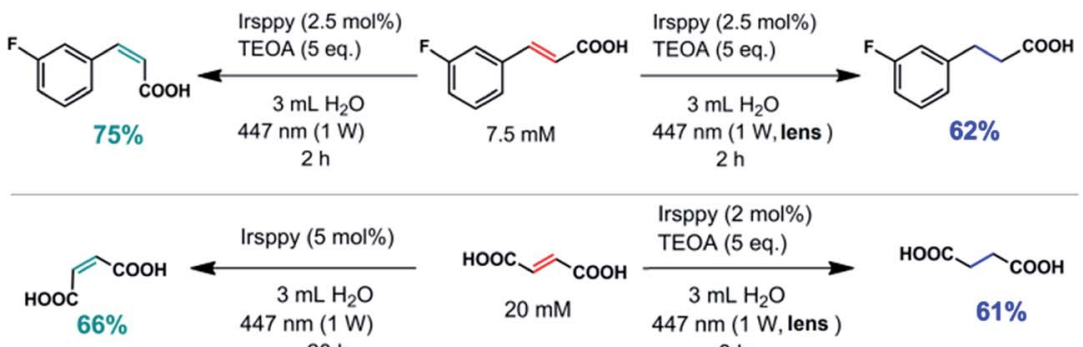

$20 \mathrm{~h}$

$3 \mathrm{~h}$
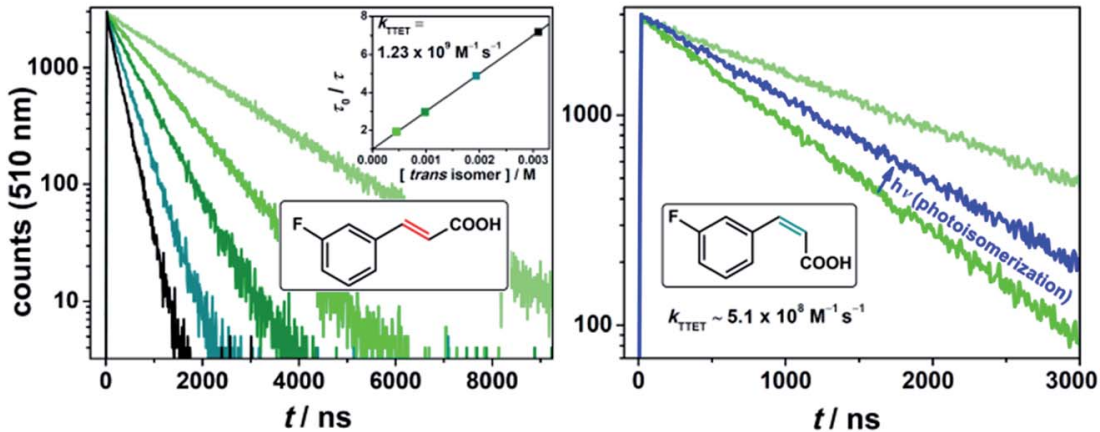

Fig. 2 trans-cis Isomerization (left, one-photon mechanism) and hydrogenation (right, two-photon mechanism) with the olefinic substrates trans-3-fluorocinnamic acid and fumaric acid using the blue-light driven photocatalytic system in Ar-saturated solutions. The lower part of the figure shows a Stern-Volmer analysis for the triplet-triplet energy transfer (TTET) between ${ }^{3}$ Irsppy and trans-3-fluorocinnamic acid (left); the rate constant for the TTET with the corresponding cis isomer was estimated using a $3: 1$ (cis-to-trans) mixture of both isomers as quencher (photostationary state, right). Further details are given in the text and Section 2.1 of the ESI. $\dagger$

photochemistry, because this approach does not rely on the prior isolation and purification of cis olefins. These results indicate that the triplet state of cis-3-fluorocinnamate is slightly higher in energy than ${ }^{3}$ Irsppy, and they are in accordance with the cis isomer being the main product in the photoequilibrium.

A plausible reaction mechanism for the formation of the hydrogenated product (right part of the upper equation in Fig. 2) is provided by: (i) initial one-electron reduction of the cinnamate ion by $\mathbf{e}_{\mathrm{aq}} \cdot{ }^{-{ }^{-44}}$ (ii) protonation of the so-obtained radical dianion, ${ }^{50}$ and (iii) hydrogen atom abstraction from electron donor (TEOA)-derived species by the protonated radical anion $^{32}$ to form the final product.

Next, we tried to apply our novel TTET-to-ET switch strategy to the substrate fumaric acid, which exists as dianion under our alkaline conditions (see Sections 3.2 and 3.4 of the ESI for details $\dagger$ and ${ }^{1} \mathrm{H}$ NMR spectra). Similar results for the hydrogenation of that substrate were obtained (lower reaction equations in Fig. 2), but only very low yields of the desired cis isomer maleic acid - were observed under similar conditions $(2 \%$ catalyst loading and $3 \mathrm{~h}$ of irradiation) for the corresponding one-photon reaction. The irradiation of our system for $20 \mathrm{~h}$ with significantly increased catalyst loading, however, resulted in a good yield of maleic acid (Fig. 2). The much slower isomerization reaction rate for fumarate compared to cinnamates can be rationalized by the high triplet energy of fumarate ${ }^{51}$ resulting in a slightly endergonic TTET step with a concomitantly low ${ }^{3}$ Irsppy quenching efficiency under our experimental conditions (see also Section 2.1 of the ESI $\dagger$ ). The photoreduction under two-photon excitation conditions proceeded very smoothly within $3 \mathrm{~h}$ for the fumaric acid substrate.
The experiments presented in this section establish that our novel reactivity control approach allows carrying out either onephoton induced double bond isomerization reactions or twophoton induced hydrogenation of the very same substrate under comparable conditions. The underlying product forming key steps are fundamentally different although the same catalyst is employed.

\subsection{Differentiating between hydrogen abstraction and dimerization}

Finally, we address the question of whether the faster initiation of a reaction with a more energetic species $\left(\mathbf{e}_{\mathbf{a q}}{ }^{-}\right)$produced by a two-photon process might lead to a different final product distribution than a less reactive initiating species ( ${ }^{3}$ Irsppy) available from single excitation. To explore this fundamental aspect, we identified the photochemical reduction of benzyl halides to produce benzyl radicals ${ }^{\mathbf{8 , 5 2 - 5 5}}$ as a suitable test ground, because this photoreaction can yield either the hydrogen abstraction product toluene or dibenzyl as dimerization product.

Trying to perform that reaction in aqueous solution, we first used the water-soluble benzyl bromide 4-(bromomethyl)benzoic acid, but rapid hydrolysis occurred even at room temperature and $\mathrm{pH}$ 7. To overcome this inherent hydrolysis problem of benzylic $\mathrm{C}-\mathrm{Br}$ bonds, we focused on the much more stable benzyl chlorides and selected the substrate 4 -(chloromethyl) benzoic acid, because it is not only perfectly water-soluble in its carboxylate form but also stable in alkaline solution on the timescales of our experiments. 

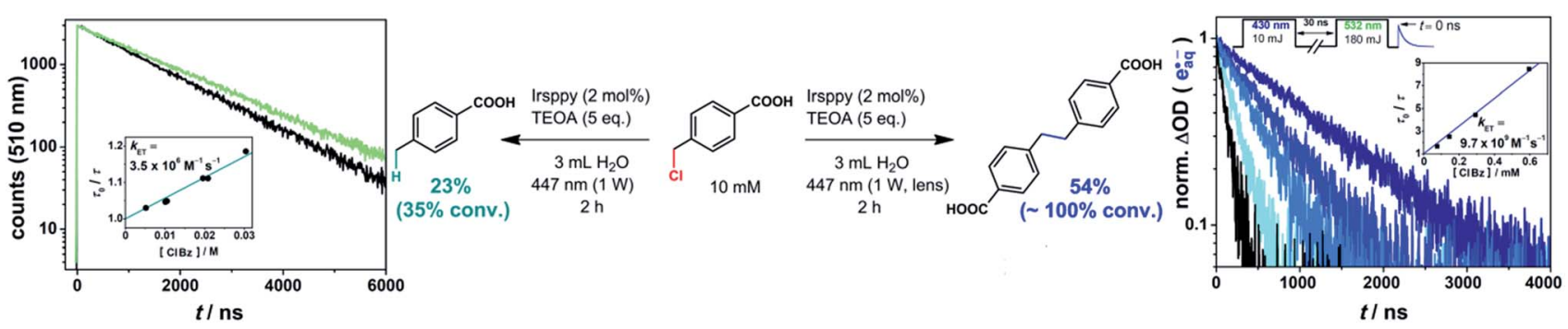

Fig. $3{ }^{3}$ Irsppy (left) and $\mathrm{e}_{\mathrm{aq}}{ }^{--}$(right) induced reductive activation of 4-(chloromethyl)benzoic acid resulting in the hydrogen abstraction and the dimerization main product, respectively, together with rate constant determinations of the two substrate activation reactions. The conditions for preparative irradiation experiments are given at the equations. For further details, see text and Section 1.3 of the ESI $\dagger$ (which enlarges on the twopulse experiments shown in the right part of the figure).

Studies on the emission quenching of ${ }^{3}$ Irsppy by 4 -(chloromethyl)benzoate (left plot in Fig. 3) gave a rate constant that is about three orders of magnitude slower than the diffusion limit $\left(3.5 \times 10^{6} \mathrm{M}^{-1} \mathrm{~s}^{-1}\right)$. This slow substrate activation is in line with the expected low driving force for this reaction as the reduction of benzyl chlorides is known to be more challenging than that of the corresponding bromides. In agreement with these findings, the preparative photoreaction is very slow with our "onephoton" setup: after $2 \mathrm{~h}$ of intense $(1 \mathrm{~W})$ irradiation (left part of the equation in Fig. 3) we observed a conversion of $35 \%$ only (compare Section 2.2, in which we reached the reaction end point in less than $2 \mathrm{~h}$ under similar conditions), and there are still remaining substrate molecules after $7 \mathrm{~h}$ reaction time $(91 \%$ conversion). These two experiments gave the hydrogen abstraction main product (4-methylbenzoic acid) in $66 \%$ and $70 \%$ conversion-normalized yields, respectively (details concerning the analytics are given in Chapter 3 of the ESI $\dagger$ ).

Carrying out the 4-(chloromethyl)benzoate activation with the very same starting solution and light output of our cw laser, but using the lens for beam collimation ("two-photon conditions"), we observed a substantial change of the reaction performance (right part of the equation in Fig. 3). The whole substrate is consumed after $2 \mathrm{~h}$, corresponding to an increase in the overall reaction rate by a factor of at least three, although only a very small fraction of the reaction volume is illuminated with the two-photon setup (compare, photographs displayed in Scheme 1). In direct consequence, the local benzyl radical concentration in the illuminated area has to be higher by orders of magnitudes when the setup with the lens is employed, which, as we found, promotes dimerization ( $54 \%$ yield). To sum up these results: applying a higher photon flux per area to the reductive activation of a water-soluble benzyl chloride - simply by using a lens - increases the reaction rate drastically, and allows to switch from the hydrogen abstraction to the dimerization main product. As in the preceding sections, these results provide clear evidence for a mechanistic change when the laser beam is collimated. Under so-called one-photon conditions, the reductive dechlorination is driven by ${ }^{3}$ Irsppy, but with the collimated beam allowing efficient $\mathbf{e}_{\mathbf{a q}}{ }^{\cdot-}$ formation, the latter reductant with its much higher reducing power operates. Using our previously developed and optimized setup for two-pulse laser flash photolysis, ${ }^{25,56-58}$ we generated hydrated electrons in the presence of several 4-(chloromethyl)benzoate concentrations and observed the expected superincrease of the substrate activation reaction rate in direct manner (right plot in Fig. 3, details are given in Section 1.3 of the ESI $\dagger$ ).

A related $\mathbf{e}_{\mathrm{aq}}{ }^{-{ }^{-}}$induced dimerization procedure in aqueous solution has been published very recently. ${ }^{18}$ In that system, the $\mathbf{e}_{\mathbf{a q}}{ }^{-{ }^{-}}$formation step requires a pulsed UV laser and a sophisticated micellar system to enable the formation of dimers. However, owing to the micellar shielding of potential hydrogen atom donors, even the efficient dimerization of very reactive radicals is possible with that approach.

The experiments of this section illustrate the effect of the 3000 -fold acceleration of a substrate activation rate constant (see rate constants included in Fig. 3). Changing the reactivity of the initiating species, which we control with the photon flux per area, allows controlling the main product, when both hydrogen abstraction and dimerization pathways of intermediates are conceivable.

\section{Conclusions}

As has emerged from this work, the combination of a single photocatalytic system - i.e., photocatalyst, solvent and sacrificial reagent - and a blue cw light source can be exploited for a variety of chemical reactions. Specifically, using our system the very same substrate can even be selectively converted into different main products under very similar conditions. The key for this reactivity control is the modulation of the light intensity per area, which we realize with inexpensive optics for beam collimation, thus allowing to switch from one- to two-photon substrate activation chemistry. As has been noted recently, ${ }^{59}$ photocatalysis is becoming an increasingly mature field in which further innovation crucially depends on in-depth mechanistic investigations. Our study follows that philosophy.

The findings presented herein on controlled substrate activation through light-power-density regulation might well stimulate a broader application of this concept in the continuouslygrowing field of photo(redox) catalysis. Possible further directions include the incorporation of our approach into cascadetype reactions, in which triplets ${ }^{28,38,60-66}$ or intermediate radicals $^{43,67-69}$ are trapped by further additives resulting in more 
valuable photochemical products, or the adaption of our methodology for reactivity control in several other solvents.

\section{Conflicts of interest}

There are no conflicts to declare.

\section{Acknowledgements}

Financial support provided by the Swiss National Science Foundation (grant number 200021_178760) and by the German National Academy of Sciences Leopoldina (postdoctoral fellowship LPDS 2017-11) is gratefully acknowledged. We thank Björn Pfund for skillful experimental support and Dr Xingwei Guo for providing us with the catalyst Irsppy.

\section{References}

1 S. Fukuzumi and K. Ohkubo, Chem. Sci., 2013, 4, 561-574.

2 N. A. Romero and D. A. Nicewicz, Chem. Rev., 2016, 116, 10075-10166.

3 Y. Du, R. M. Pearson, C.-H. Lim, S. M. Sartor, M. D. Ryan, H. Yang, N. H. Damrauer and G. M. Miyake, Chem.-Eur. J., 2017, 23, 10962-10968.

4 E. Speckmeier, T. G. Fischer and K. Zeitler, J. Am. Chem. Soc., 2018, 140, 15353-15365.

5 M. Reckenthäler and A. G. Griesbeck, Adv. Synth. Catal., 2013, 355, 2727-2744.

6 D. M. Arias-Rotondo and J. K. McCusker, Chem. Soc. Rev., 2016, 45, 5803-5820.

7 J. M. R. Narayanam and C. R. J. Stephenson, Chem. Soc. Rev., 2011, 40, 102-113.

8 C. K. Prier, D. A. Rankic and D. W. C. MacMillan, Chem. Rev., 2013, 113, 5322-5363.

9 T. Koike and M. Akita, Inorg. Chem. Front., 2014, 1, 562-576.

10 Y. Qiao and E. J. Schelter, Acc. Chem. Res., 2018, 51, 29262936.

11 O. S. Wenger, J. Am. Chem. Soc., 2018, 140, 13522-13533.

12 B. M. Hockin, C. Li, N. Robertson and E. Zysman-Colman, Catal. Sci. Technol., 2019, 9, 889-915.

13 S. Protti, D. Ravelli and M. Fagnoni, Photochem. Photobiol. Sci., 2019, 18, 2094-2101.

14 M. Neumeier, D. Sampedro, M. Májek, V. A. de la Peña O'Shea, A. Jacobi von Wangelin and R. Pérez-Ruiz, Chem.Eur. J., 2018, 24, 105-108.

15 I. Ghosh and B. König, Angew. Chem., Int. Ed., 2016, 55, 7676-7679.

16 A. M. Martínez-Gualda, R. Cano, L. Marzo, R. Pérez-Ruiz, J. Luis-Barrera, R. Mas-Ballesté, A. Fraile, V. A. de la Peña O'Shea and J. Alemán, Nat. Commun., 2019, 10, 2634.

17 U. Lachish, A. Shafferman and G. Stein, J. Chem. Phys., 1976, 64, 4205-4211.

18 T. Kohlmann, C. Kerzig and M. Goez, Chem.-Eur. J., 2019, 25, 9991-9996.

19 M. A. Miranda, J. Pérez-Prieto, E. Font-Sanchis and J. C. Scaiano, Acc. Chem. Res., 2001, 34, 717-726.
20 J. C. Scaiano, L. J. Johnston, W. G. McGimpsey and D. Weir, Acc. Chem. Res., 1988, 21, 22-29.

21 D. N. Nikogosyan, Int. J. Radiat. Biol., 1990, 57, 233-299.

22 T. Kohlmann, R. Naumann, C. Kerzig and M. Goez, Photochem. Photobiol. Sci., 2017, 16, 1613-1622.

23 I. Ghosh, T. Ghosh, J. I. Bardagi and B. König, Science, 2014, 346, 725-728.

24 M. Goez, C. Kerzig and R. Naumann, Angew. Chem., Int. Ed., 2014, 53, 9914-9916.

25 C. Kerzig, X. Guo and O. S. Wenger, J. Am. Chem. Soc., 2019, 141, 2122-2127.

26 K. C. Harper, E. G. Moschetta, S. V. Bordawekar and S. J. Wittenberger, ACS Cent. Sci., 2019, 5, 109-115.

27 X. Guo, Y. Okamoto, M. R. Schreier, T. R. Ward and O. S. Wenger, Chem. Sci., 2018, 9, 5052-5056.

28 F. Strieth-Kalthoff, M. J. James, M. Teders, L. Pitzer and F. Glorius, Chem. Soc. Rev., 2018, 47, 7190-7202.

29 G. V. Buxton, C. L. Greenstock, W. P. Helman and A. B. Ross, J. Phys. Chem. Ref. Data, 1988, 17, 513-886.

30 C. Kerzig and M. Goez, Chem. Sci., 2016, 7, 3862-3868.

31 X. Li, J. Ma, G. Liu, J. Fang, S. Yue, Y. Guan, L. Chen and X. Liu, Environ. Sci. Technol., 2012, 46, 7342-7349.

32 Y. Pellegrin and F. Odobel, C. R. Chim., 2017, 20, 283-295.

33 J. A. Murphy, J. Org. Chem., 2014, 79, 3731-3746.

34 M. Claros, F. Ungeheuer, F. Franco, V. Martin-Diaconescu, A. Casitas and J. Lloret-Fillol, Angew. Chem., Int. Ed., 2019, 58, 4869-4874.

35 A. U. Meyer, T. Slanina, A. Heckel and B. König, Chem.-Eur. J., 2017, 23, 7900-7904.

36 S. Berger, S. Braun and H.-O. Kalinowski, NMR Spektroskopie von Nichtmetallen, vol. 4, ${ }^{19}$ F-NMR-Spektroskopie, Thieme, Stuttgart, 1994.

37 H.-X. Gong, Z. Cao, M.-H. Li, S.-H. Liao and M.-J. Lin, Org. Chem. Front., 2018, 5, 2296-2302.

38 A. Hölzl-Hobmeier, A. Bauer, A. V. Silva, S. M. Huber, C. Bannwarth and T. Bach, Nature, 2018, 564, 240-243.

39 E. R. Welin, C. Le, D. M. Arias-Rotondo, J. K. McCusker and D. W. C. MacMillan, Science, 2017, 355, 380-385.

40 J. B. Metternich and R. Gilmour, J. Am. Chem. Soc., 2016, 138, 1040-1045.

41 J. J. Molloy, T. Morack and R. Gilmour, Angew. Chem., Int. Ed., 2019, 58, 13654-13664.

42 M. Bhadra, S. Kandambeth, M. K. Sahoo, M. Addicoat, E. Balaraman and R. Banerjee, J. Am. Chem. Soc., 2019, 141, 6152-6156.

43 R. Naumann, F. Lehmann and M. Goez, Chem.-Eur. J., 2018, 24, 13259-13269.

44 M. Brautzsch, C. Kerzig and M. Goez, Green Chem., 2016, 18, 4761-4771.

45 M. Montalti, A. Credi, L. Prodi and M. T. Gandolfi, Handbook of photochemistry, CRC/Taylor \& Francis, Boca Raton, 3rd edn, 2006.

46 R. Naumann, F. Lehmann and M. Goez, Angew. Chem., Int. Ed., 2018, 57, 1078-1081.

47 P. Debye, Trans. Electrochem. Soc., 1942, 82, 265.

48 C. Kerzig and M. Goez, Phys. Chem. Chem. Phys., 2015, 17, 13829-13836. 
49 S. E. Boiadjiev and D. A. Lightner, J. Phys. Org. Chem., 1999, 12, 751-757.

50 V. D. Parker, Acta Chem. Scand., Ser. B, 1981, 35, 295-301.

51 M. J. Mirbach, M. F. Mirbach and A. Saus, J. Photochem., 1982, 18, 391-393.

52 C. B. Larsen and O. S. Wenger, Inorg. Chem., 2018, 57, 29652968.

53 Y. Zhang, J. L. Petersen and C. Milsmann, J. Am. Chem. Soc., 2016, 138, 13115-13118.

54 G. Park, S. Y. Yi, J. Jung, E. J. Cho and Y. You, Chem.-Eur. J., 2016, 22, 17790-17799.

55 T. C. Jenks, M. D. Bailey, J. L. Hovey, S. Fernando, G. Basnayake, M. E. Cross, W. Li and M. J. Allen, Chem. Sci., 2018, 9, 1273-1278.

56 S. Neumann, C. Kerzig and O. S. Wenger, Chem. Sci., 2019, 10, 5624-5633.

57 M. Kuss-Petermann and O. S. Wenger, Helv. Chim. Acta, 2017, 100, e1600283.

58 M. Skaisgirski, C. B. Larsen, C. Kerzig and O. S. Wenger, Eur. J. Inorg. Chem., 2019, DOI: 10.1002/ejic.201900453.

59 L. Buzzetti, G. E. M. Crisenza and P. Melchiorre, Angew. Chem., Int. Ed., 2019, 58, 3730-3747.
60 F. M. Hörmann, T. S. Chung, E. Rodriguez, M. Jakob and T. Bach, Angew. Chem., Int. Ed., 2018, 57, 827-831.

61 T. R. Blum, Z. D. Miller, D. M. Bates, I. A. Guzei and T. P. Yoon, Science, 2016, 354, 1391-1395.

62 X. Huang, T. R. Quinn, K. Harms, R. D. Webster, L. Zhang, O. Wiest and E. Meggers, J. Am. Chem. Soc., 2017, 139, 9120-9123.

63 F. Strieth-Kalthoff, C. Henkel, M. Teders, A. Kahnt, W. Knolle, A. Gómez-Suárez, K. Dirian, W. Alex, K. Bergander, C. G. Daniliuc, B. Abel, D. M. Guldi and F. Glorius, Chem, 2019, 5, 2183-2194.

64 M. E. Daub, H. Jung, B. J. Lee, J. Won, M.-H. Baik and T. P. Yoon, J. Am. Chem. Soc., 2019, 141, 9543-9547.

65 V. K. Soni, H. S. Hwang, Y. K. Moon, S.-W. Park, Y. You and E. J. Cho, J. Am. Chem. Soc., 2019, 141, 10538-10545.

66 Y. Kobayashi, K. Mutoh and J. Abe, J. Photochem. Photobiol., $C, 2018,34,2-28$.

67 M. Majek and A. Jacobi von Wangelin, Acc. Chem. Res., 2016, 49, 2316-2327.

68 I. Ghosh, L. Marzo, A. Das, R. Shaikh and B. König, Acc. Chem. Res., 2016, 49, 1566-1577.

69 T. Patra, S. Mukherjee, J. Ma, F. Strieth-Kalthoff and F. Glorius, Angew. Chem., Int. Ed., 2019, 58, 10514-10520. 